\title{
Assisted Learning Systems in e-Education
}

\author{
Gabriel ZAMFIR \\ Department of Economic Informatics and Cybernetics, \\ The Bucharest University of Economic Studies, Romania, \\ gabriel.zamfir@ie.ase.ro
}

\begin{abstract}
Human society, analyzed as a learning environment, presumes different languages in order to know, to understand or to develop it. This statement results as a default application of the cognitive domain in the educational scientific research, and it highlights a key feature: each essential discovery was available for the entire language compatible society. E-Society is constructed as an application of E-Science in social services, and it is going to reveal a learning system for each application of the information technology developed for a compatible society. This article is proposed as a conceptual one focused on scientific research and the interrelationship between the building blocks of research, defined as an engine for any designed learning system applied in the cognitive domain. In this approach, educational research become a learning system in e-Education. The purpose of this analysis is to configure the teacher assisted learning system and to expose its main principles which could be integrated in standard assisted instruction applications, available in e-Classroom, supporting the design of specific didactic activities.
\end{abstract}

Keywords: Research Methodologies, Educational Research, E-Science, E-Education Infrastructure, E-Classroom

1 Introduction

The analysis of this study is built on the paradigm of the triangle lexical, terminological and conceptual approach, presented as a three layers research methodology for an educational environment. A case study is started for the word 'society', which lexically, has a multiple common-sense meanings. The most abstract sense of it is concentrated in expressions such as "the information society", "the knowledge society" or "the learning society"; in this case, the perspective is the cognitive domain and no limitations are included. These are different representations of the same global community, and as another lexical exercise, globalization is used to describe the international community by the users of the global information system and to explain the international community by the designers of the same society. The three senses are reflecting the first three stages of the Bloom taxonomy: knowledge, comprehension, and application. We use these three concepts as a building block for a learning system, and as a scaffold of the pyramid of specific terms. Passing the lexical level, we develop a terminological analyze, in a socio- logical approach, where [1] concludes that the common-sensical meaning of 'society' have three features in common: first, each refers to networks of people relating to each other in some meaningful way, even if indirectly; second, there are criteria of membership, and therefore there is some sense of inclusive - and therefore necessarily exclusive - boundedness; and third, each conveys a sense of ways of doing things in common, of characteristic patterns of behavior, of organization. For an educational approach, this represents the two next stages of the Bloom taxonomy: analysis and synthetizing using the network's terms of the domain. These meanings of 'society' also suggest that there is widespread recognition that there is something more for everyday life than the embodied obviousness of individuals. The same author considers that talking about how we can perceive the collective more-than-the-sumof-the-parts move the discussion on the epistemology: how are we to know and understand the human-made world? In the educational approach, at this level, we identify the sixth stage of the Bloom taxonomy: evaluation, in order to intend a scientific methodol- 
ogy for an educational research. Before answering that question, [1] considers that it is necessary to clarify the relationship between ontology and epistemology.

According to [2], there are several reasons for wanting to have a clear and transparent knowledge of the ontological and epistemological assumptions that underpin research: first, to understand the interrelationship of the key components of research, including methodology and methods; second, to avoid confusion when discussing theoretical debates and approaches to social phenomena; and third, to be able to recognize others', and defend our own, positions. Ontology is the starting point of all research, after which one's epistemological and methodological positions logically follow. In [3] the author explains that there are two distinct but related senses of the word ontology: its technical computer science sense, associated with the World Wide Web, and its technical philosophical sense; when confusion is possible, the first is called "computer" or "computational" ontology, and the second "philosophical" or "formal" ontology.

Knowledge, and the ways of discovering it, are not static, but forever changing. Continuing the idea, [4] highlights the fact that epistemology sustains the researcher to generate knowledge and explanations about the ontological components of the social world, be they social processes, social actions, discourses, meanings, or whatever, which he has identified as central. There may be lots of possibilities and, the researchers must recognize not only that there is more than one epistemology, but also that they will not all be complementary or equally consistent with their own ontological position. At the same time, starting from the definition of 'terminology', [5] concludes that we can realize clearly that this word is connected with specific subject field, and it can be describe as a structured set of concepts that clarify and put bases for a particular subject field or as an infrastructure of specialized knowledge. The same author focuses on exposing the impact of the lexical problems upon translation of the economic terminology. Lexical problems usually occur when the meaning of the word or the expression in the language is not understood, or totally were unknown terms to the translator, synonymy, polysemy, collocations, metaphors and idioms are the most common lexical problems. A complementary perspective of the analysis is investigated in [6]; the author aims to show, in a summarized way, how different studies on metaphor can positively converge to a cognitivelinguistic perception of this phenomenon. It is concluded that metaphor is one of the phenomena that make part of the technical and scientific communication and, because of the complexity in approaching such topic, it must also investigated in Terminology. It is recognized the existence of two possible approaches on metaphor: the rhetoric conception and the semantic conception. The metaphoric neologisms that integrate a specific terminology are related to the process of creative analogical thinking. These neologisms, or neolexicalizations, would be a result of deep analogies used to creative understanding or didactic purposes.

As indicated by Greek etymology, metaphor means "transference" and lead us to interdisciplinary or trans-disciplinary approaches, which have to be exactly delimited for an object language or for a meta-language context. Such a description could explain the use of metaphors in specific context such as academic discourse or classroom interaction. In [7] the author defines the metaphor as a mapping across domains, where each mapping is a set of ontological correspondences between entities in a source domain and those in a target one. The analysis of metaphor involves the use of two traditional notions: Topic and Vehicle; the first one refers to the literal entity in the world of the text about which something is predicated in a figurative manner, or to which a non-literal predicate is attached. This figurative predicate is called the Vehicle. The conceptual metaphor has been used to build up a conceptual system, correlated with the cognitive infrastructure of the researcher. As soon as the cognitive infrastructure is the result of learning, scientific research reflects methodolo- 
gies for a learning system. In an e-society, knowledge and cognitive infrastructures are two applications of e-science, first in technology and the second, in the educational infrastructure, as they are presented in the paradigm of learning in a scientific environment [8]. The same paradigm presents knowledge and cognitive infrastructure as other two applications of Terminologies, first in a specific language and the second, in a particular concept map. In this context, learning is defined as an application of a cognitive infrastructure in knowledge, in order to convert tacit knowledge in explicit knowledge.

Analyzed as a human-made world, a learning society requires a language with a triple phase for a concept within a terminology using a lexicon: knowledge, comprehension, and application.

\section{Knowledge Framework}

Based on the same methodological approach presented in [8], scientific research is defined as a paradigm between theory and practice, developed for an object language using an updated meta-language. The possibility of using the same term in the group of the working terms and in the group of the scientific field's terms lead to the situation of describing or explaining a paradox. In fact, these are the two functions of the meta-language, which represent the first two stages of learning: knowledge and comprehension. The third stage, the application is implemented as a pattern of the object language. Technological innovation in a digital environment depends on the pattern of educational change in the pedagogical environment, when this is an application of the technological infrastructure.

The idea of an innovative learning system was published in 1950, when [9] mentioned in the introductory section that the paper was concerned with the problem of constructing a computing routine or "program" for a modern general purpose computer which will enable it to play chess. The author considered that although perhaps of no practical importance, the question was of theoretical interest, and it was hoped that a satisfactory so- lution of this problem will act as a wedge in attacking other problems of a similar nature and of greater significance. There were listed directions as: machines for designing filters, equalizers, relay and switching circuits, machines which will handle routing of telephone calls based on the individual circumstances rather than by fixed patterns; machines for performing symbolic mathematical operations, machines capable of translating from one language to another, machines for making strategic decisions in simplified military operations, machines capable of orchestrating a melody, and machines capable of logical deduction. In August 2013, at Yokohama in Japan it was organized the $20^{\text {th }}$ World Computer Championship. There were two main tournaments: an unlimited hardware World Computer Chess Championship and an equal hardware World Chess Software

Championship (http://www.hiarcs.com/Games/wccc13/wccc 2013.htm).

In 1983, in [10] it was mentioned that Machine Learning was been a constant theme throughout AI's two decades of existence. In this overview the authors were analyzing various aspects including the major methodological approaches advocated in Machine Learning research, and how they had related to major contemporary themes in "mainstream" AI Research. According to the authors, learning is a many-faceted phenomenon. Learning processes include the acquisition of new declarative knowledge, the development of motor and cognitive skills through instruction or practice, the organization of new knowledge into general, effective representations, and the discovery of new facts and theories through observation and experimentation. The study and computer modelling of learning processes in their multiple manifestations constitutes the subject matter of machine learning.

In 2014, in [11] the author's main research activity is framed within machine learning, data mining and their application to relevant computational biology problems ranging from basic molecular biology to medicine. This information is developed as an applica- 
tion of cybernetics in science, as soon as cybernetics was formulated by its founders as a meta-discipline with the aim of collaboration between disciplines (inter-disciplinary) and of sharing knowledge across disciplines (trans-disciplinary). As meta-discipline, cybernetics integrates ontology as forms of knowledge and epistemology as forms of knowing. One example of this approach is the Brain Gate Neural Interface System developed to sense, transmit, analyze and apply the language of neurons. Two applications of the Brain-Computer Interface as learning system are: activating control of mobile robot by human brain electrical activity and evaluating the machine learning procedures [12]. This situation reflects the computer as a physical extension of the human brain. A second example of the integration of forms of knowledge and forms of knowing is represented by augmented reality, where the computer is reflected as a psychological extension of the human brain. In this case, augmented reality can be used to encourage understanding and mastery of the real world therefore resulting in an augmented perception of reality as it exists in the present; at the same time, augmented reality can propose an artificial environment that represent some past or future reality, or even an impossible reality [13].

The third example of this approach is represented by the personal computer as a cognitive extension of the human brain, and the system is a teacher assisted learning. As it is analyzed in [14], the learning system based on a teacher assisted activity is a dynamic one and the concept is developed on three kinds of infrastructure which are likely to emerge: first, technological infrastructure, the second, cognitive infrastructure of all participants involved in the teaching-learning activities, and the third, conceptual infrastructure of the type of the study programmes. Technology determines new forms of knowledge and new forms of knowing too. As a consequence, all three type of infra- structure are dynamic and each of them need systematic updates. This is an explanation for developing standards for hardware, versioning policy for software, and defining standard professional and transversal competences for academic qualifications. Such an approach transforms the academic institution into a learning organization, and its infrastructures become compatible with standard economic, cultural, and political institutions.

\section{Comprehension Framework}

Social relations identified as communities, organizations, institutions, and societies are conceptualized as sets of interrelated parts with internal structures and processes. Analyzed as evolutionary entities, they become systems and represents more than the sum of its parts. Developed in an educational research, standard internal structures define learning organizations and standard processes define organizational learning. Three types of learning were identified in such a context: learning to adapt, learning to change and learning to learn. As social constructs, three type of educative systems were highlighted representing formal, non-formal and informal education. Developed as a global information system, the technological infrastructure transformed the educative systems in intranet, extranet and internet environment.

Each component of this approach became an ontology of a scientific research activity, including research activity as a circular reference. According to [2], by setting clearly the interrelationship between what the researcher thinks can be researched, linking it to what we can know about it and how to go about acquiring it, you can begin to comprehend the impact your ontological position can have on what and how you decide to study. A researcher's methodological approach underpinned by and reflecting specific ontological and epistemological assumptions represents a choice of approach and research methods adopted in a given study (see the image in Fig. 1, synthetized from [2]). 


\section{ONTOLOGY $\longrightarrow$ EPISTEMOLOGY}

Fig. 1. The interrelationship between the building blocks of research

The same author highlights that the figure shows the directional, and logical, relationship between the key components of research; what the figure doesn't show is the impact and the influence of the questions one is asking, and the type of the project one is undertaking, on the methods chosen. At the same time, the researcher may begin at any of the stages in the figure above.
According to the conceptual paradigm of learning in e-Society presented in [8], where e-science is defined as an application of the informatics technology in science, and synthesizing the approach developed in the knowledge framework in this paper, a projection of learning systems in the context of the building block of scientific research is presented in the image in Fig. 2.

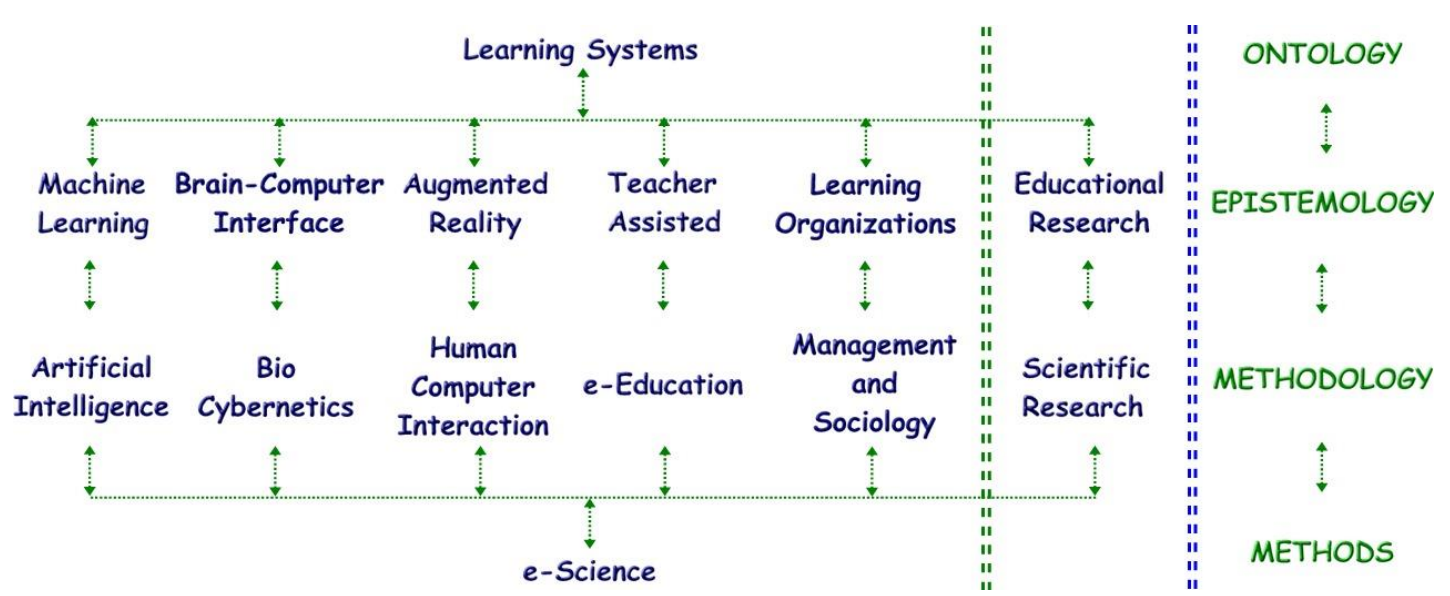

Fig. 2. The interrelationship between the building blocks of Learning Systems

Scientific research activity, using a metalanguage in order to explain the building blocks of research as different pieces of pathmaking, represents a recursive process for education, while scientific research activity, using an object-language, in order to describe different pieces of path-using, represents an application in e-science. As it was grounded in [15], both types of languages develop subjects in the background of a specific group of working terms, expanded as a meta-subject. The group of working terms has a double function: a descriptive one (knowledge function) and an explanatory one (understand function).

\section{Application Framework}

As it was presented in [14], the conditions of a theoretical framework for the development of the e-education concept there were available in the middle of the last century. The premises of e-education were structured on the three types of infrastructure: the technological one (the first computer: programmable, digital, RAM based, transistor based, commercial, and even the personal one), the conceptual infrastructure (based on the information technology domain) and the cognitive infrastructure (based on the Bloom taxonomy). These three modules represent the context, the content and the cognition, developed as the essential components of an educational research model.

The building blocks of an e-Education system starts with standards, implemented for hardware and extended for software, then formulated for data ware. These components represent modules for standard technological infrastructure, which stands for standard information systems: organizational, metropolitan, national, regional and the global information systems. All of them need identification, authentication and authorization of all users, as the basis operations for a generic 
functionality (see the image presented in Fig. 3 ). The users consist of different classes, such as: teachers, students, tutors, designers, administrators and guests. They are educated based on different conceptual infrastructure, and promote different conceptual infrastructure, permanently updated.
The main features of an e-Education system are determined by the global functionality and the diversity of the users. The technical components are developed by integration or aggregation, and the evolution of the system is a spiral one, as soon as these are drivers for human behaviour.

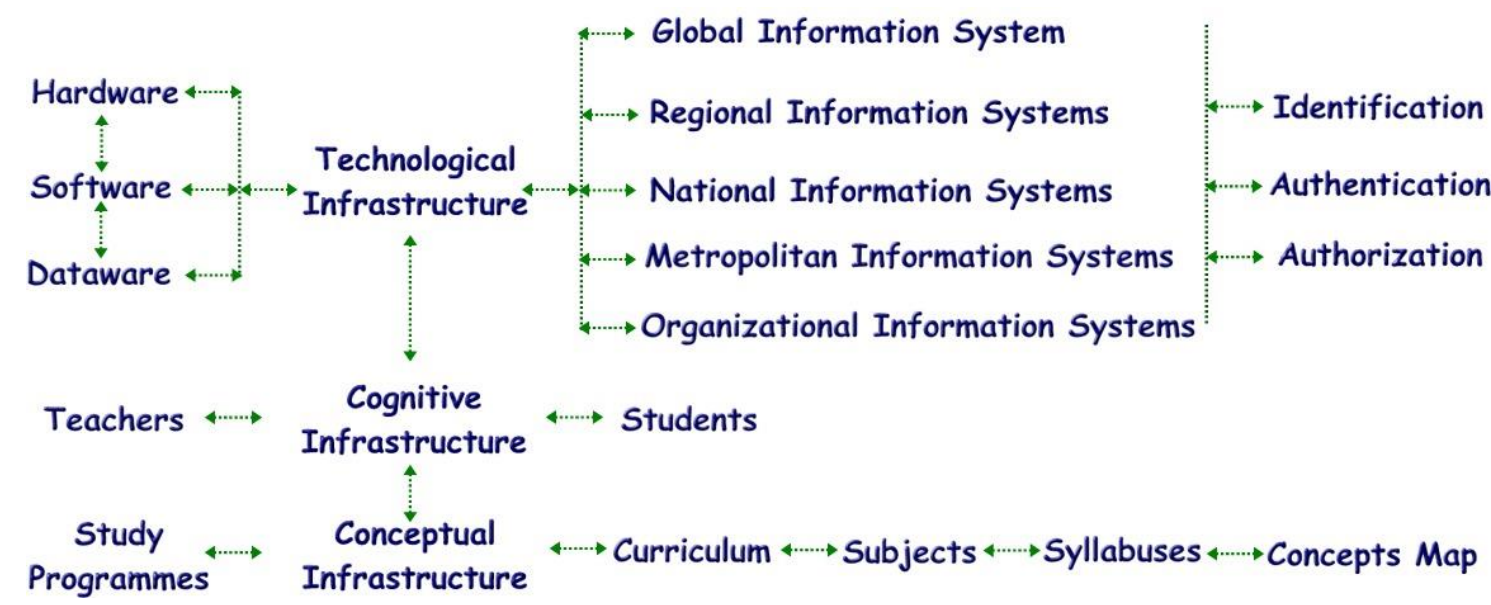

Fig. 3. The interrelationship between the building blocks of an e-Education System

The human-made world is a learning environment because of tacit knowledge. Education, as the engine of this learning environment, has the responsibility concerning knowledge conversion. According to previous researches [8], [14], and [16], in this approach the e-education is defined as an application of assisted didactic design in education and e-learning is developed as an electronic support for e-Class. E-Class represents a virtual classroom, with no restrictions regarding space and time, developed as an informatics application in e-Education based on e-Science. E-Classroom is developed as an alternative of this electronic space, representing an extension of the traditional classroom and it is constituted as the first social application of the assisted instruction in eEducation based on e-Science.

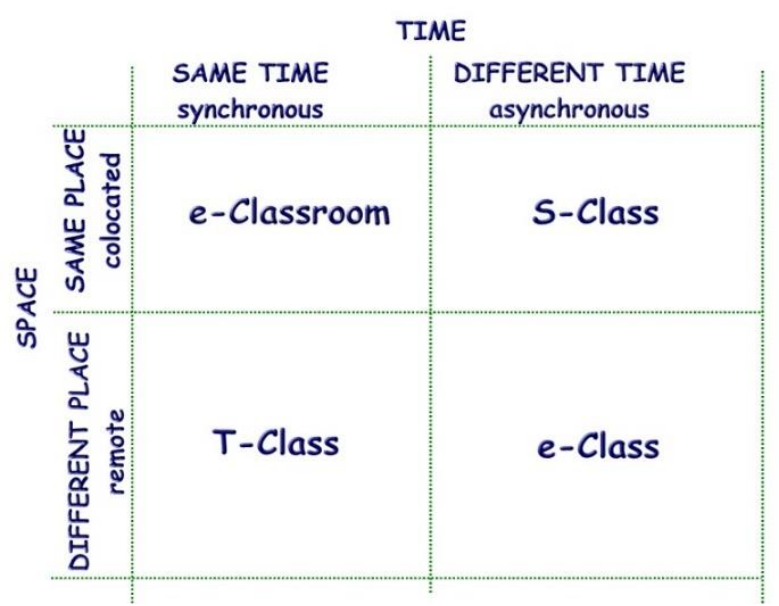

Fig. 4. Learning Systems in e-Education

E-Classroom could be designed as a learning system when it is based on an architecture consisting of a standardized technological infrastructure based environment, with stand- 
ardized professional and transversal competences for academic qualifications, and standardized conceptual infrastructure for each type of the study programmes. All three types of conditions need periodical update. Factually, first two of these settings are represented at least, by initial implementations, while a digital content developed as standard assisted instruction applications involving didactic laboratories capable to be used for creating learning objects remains a permanent objective.

E-Classroom integrates assisted instruction which consists of computer assisted instruction and teacher assisted learning. Computer assisted instruction represents the basis for individualized learning, and integrates this first principle of the teacher assisted learning system. The second principle is derived from the first one; it is personalized learning which it based on the student-own-pace feature. This functionality is founded on interactivity, which is developed as the third principle of this type of learning system and it is based on the triple-vision of the personal computer as tool, tutor and tutee.

Interactivity depends on the adequate information granularity, which represents digital content developed in a concept map approach for the conceptual infrastructure of the study programmes. Within any domain of knowledge, there is hierarchy of concepts, where the most general concepts are at the "top" of the hierarchy and the more specific, less general concepts are defined at the first level. Here are organized the basic concepts, and two or more of these can form aggregate concepts. The hierarchy contains key concepts, which determine deep understanding of different theories of the domain. The adequate information granularity represents the fourth principle of the teacher assisted learning system.

Based on these four principles, an eClassroom become an educational infrastructure with potential functionality in areas such as clarifying the zone of proximal development for a student, scaffolding learning activities, mediating learning while in progress. The granularity used for a personalized learn- ing could highlight the threshold concepts, when the face-to-face teaching reveals troublesome knowledge; these situations consist the feedback for this type of learning system and could assure the update of the conceptual infrastructure.

Computer assisted instruction is developed as a meta-discipline while it integrates interdisciplinary approaches because of the diversity as forms of knowing and transdisciplinary approaches because of diversity as forms of knowledge. These are two principles which complete the features of a teacher assisted learning system in the cognitive domain. It is necessary to know the concepts of a subjects (according to a lexical level), it is mandatory to know to apply these concepts (using a terminological level), and it is didactic to correlate them (learning at a conceptual level).

\section{Case study}

One of the conclusions argued in [16] mentioned that an e-educational scientific research program's output should become an environment of instruction for a student's study program. The student's study program's objectives consist of professional and transversal competencies and they are developed through discipline's classwork. In eClassroom, the discipline theorized emerges in the discipline practiced and both converge in a new discipline. This new discipline has to educate the new generations of trainers, as a recursive process instead of an iterative one.

Designing interactive applications for training the trainers involves the two languages of an e-educational scientific research: the meta-language and the object language.

In the following example, we develop an interactive application for assisted instruction where the user is teacher and student alternatively, and the language consists of adequate terminology in context.

Let's consider the objective: Basis spreadsheet concepts interactive approach for understanding.

Task 1: Configuring the program 
Open Excel and configure the next general options for working with this program (select File, Options, and General): When creating new workbooks: use the default font Arial, set font size: 10, and include one sheet.

Personalize your copy of Microsoft Office, editing your name as the user name.

Enable all macros selecting File, Options, and Trust Center, click the button Trust Center Settings..., and click the option Macro Settings, then select the radio button Enable all macros. In the Trust Center windows, click the option Protected View and disable all the check boxes in the section Protected View.
You have to close and restart this working session so the changes can take effect.

Task 2: Edit the properties of the program

Open the program, select File, Info and Show All Properties. Edit the Title: Basis spreadsheet concepts, Subject: Assisted Didactics Design, edit Categories: Interactive Learning, observe the Author.

Task 3: Display the properties of the program Create a procedure in order to display the properties already edited: Alt+F8, edit Properties as Macro name and press the button Create of the Macro window. Edit the content of the procedure as it is shown in Fig. 5.

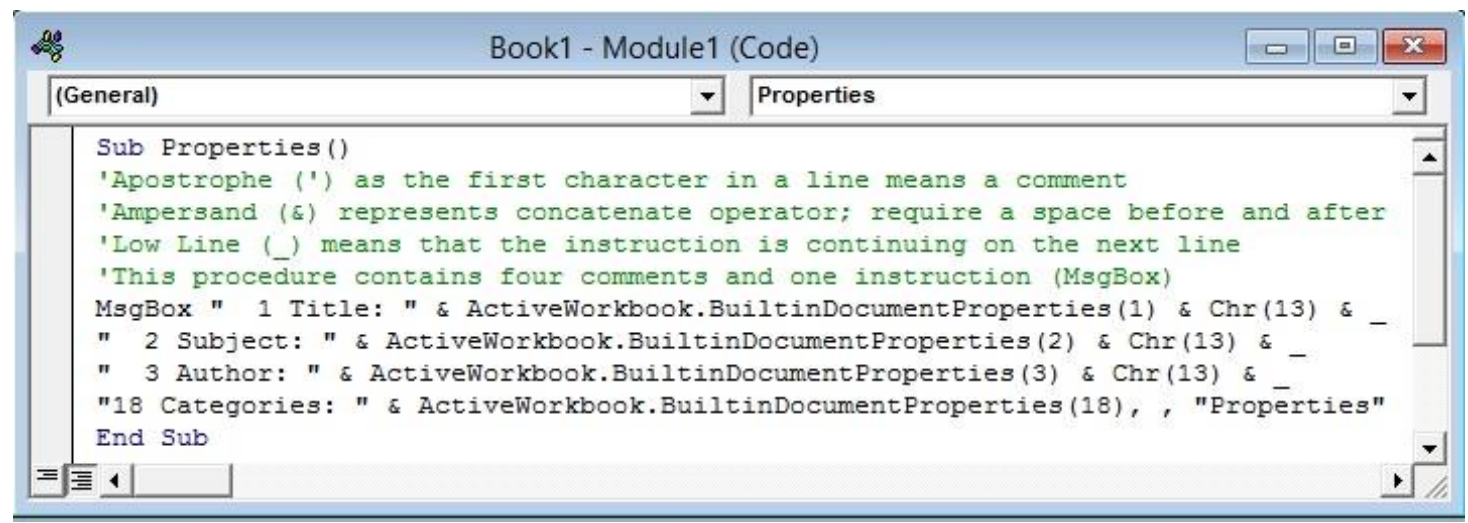

Fig. 5. Properties of the environment

Close the programming environment with Alt $+\mathrm{F} 4$, and display the properties with the command Alt+F8 and then click the button Run of the Macro window.

Task 4: Create the application Open the program, rename Sheet1 with 1: Hit the Alt key, then type HOR (one key at a time), type 1 and press Enter. Resize columns B:H at 70 pixels: $C t r l+\mathrm{G}$, edit $\mathrm{B}: \mathrm{H}$ press Enter, and resize one column from se- lection. Insert a text box in the range B2:H4 using one of the two methods:

a) Click Insert $>$ in the Text group > click Text Box, looking for the icon $\mathrm{A}$ and draw the text box in the specified range, or

b) Hit the Alt key, then type NX (one key at a time) then draw the text box in the specified range.

Edit in the text box the statement of the exercise (see the image in Fig. 6).

\begin{tabular}{|c|c|c|c|c|c|c|c|c|}
\hline \multicolumn{2}{|c|}{ TextBox 1} & $\rightarrow$ & \multicolumn{6}{|c|}{$: \times \vee f_{x}$} \\
\hline 4 & A & B & C & D & $E$ & $\mathrm{~F}$ & G & $\mathrm{H}$ \\
\hline \multicolumn{9}{|l|}{1} \\
\hline 2 & & \multirow{3}{*}{\multicolumn{7}{|c|}{$\begin{array}{l}\text { Select the range R2:AA6 then click the button labelled } 1 . \\
\text { See the button labelled } 1 \text { in the range Z8:AA9. }\end{array}$}} \\
\hline 3 & & & & & & & & \\
\hline$\frac{4}{5}$ & & & & & & & & \\
\hline 5 & & & & & & & & \\
\hline 6 & & & & & & & & \\
\hline
\end{tabular}

Fig. 6. The statement of the exercise 
A similar visual effect could be obtained merging the cells in the range $\mathrm{B} 2: \mathrm{H} 4$

Task 5: Develop the interactivity creating a procedure assigned to an interface object

This program has two types of controls: Form controls and ActiveX Control. They are available in the Developer menu, which can be permanent visible in Ribbon selecting File, Options, and Customize Ribbon; in section Customize the Ribbon click the check box Developer. In addition to these, the user can add also objects from the Drawing tools.
In order to solve the statement of the exercise, we insert a button in the range Z8:AA9, selecting the menu-button Insert, which can be found in the group Controls of the menu Developer in the Ribbon. Click the first object Button (Form Control) in the Form Controls list and draw the button in the range Z8:AA9. An Assign Macro window will be open; click the command-button $\mathrm{New}$ in the active window.

Edit the content of the procedure as it is shown:

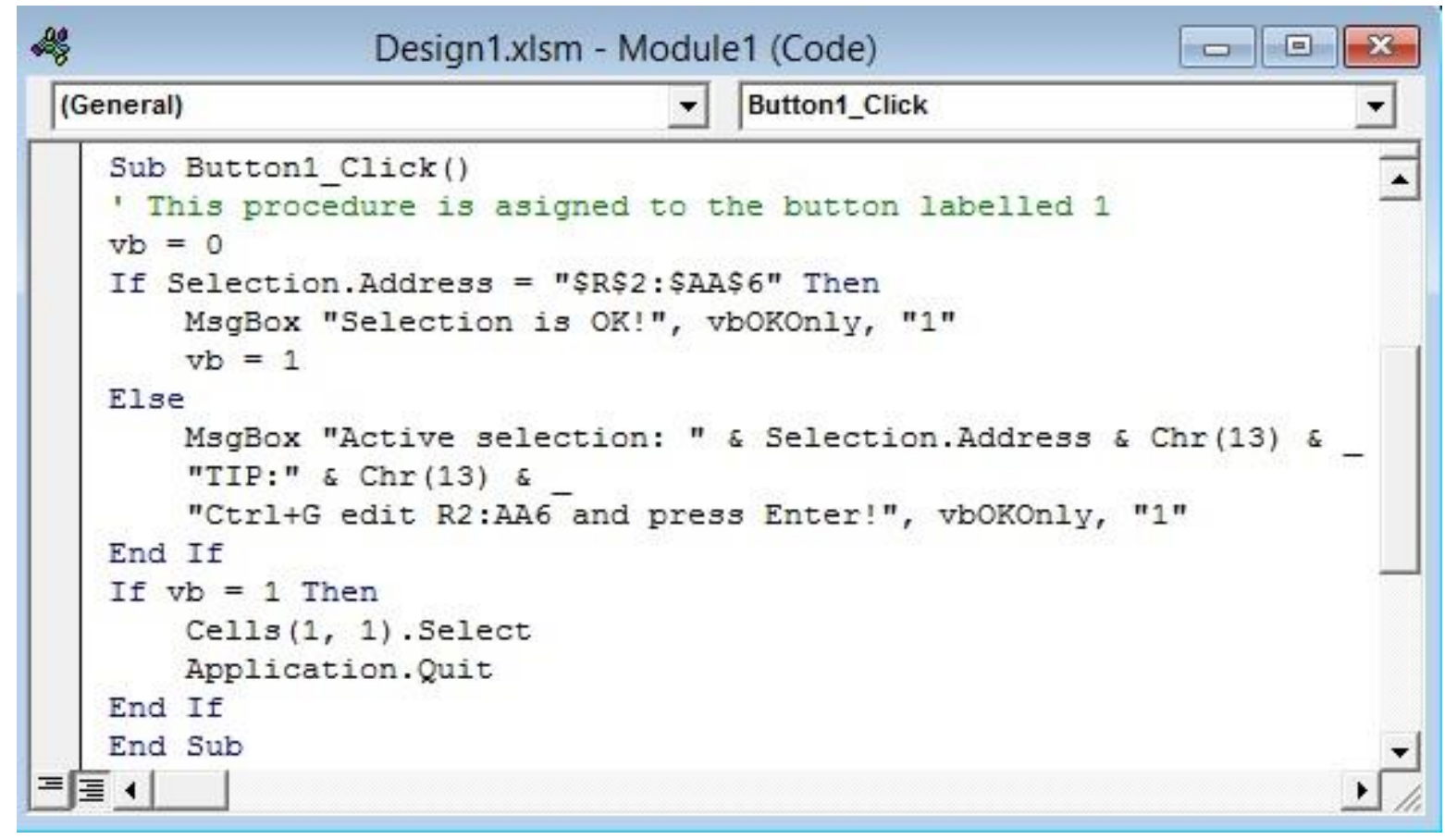

Fig. 7. The procedure assigned to the interface object

Close the active window $(A l t+\mathrm{F} 4)$ and edit text of the button, changing his label from Button 1 to 1.

Task 6: Save the application

Save the application containing the exercise with the name Design1 in Excel MacroEnabled Workbook (*.xlsm) format.

Task 7: Test the functionality and check the $\underline{\text { messages }}$

As a student, opening the application, reading the statement, scrolling the spreadsheet and clicking the button, it is displayed a window consisting of a message about how to proceed to solve the exercise. If the action of the user is correct and the exercise is solved, it is displayed a window confirming the success, and the application is closed. If the user's action is not correct, when the he is clicking the button, he can read a method; the application is closed when the user's action is correct, solving the exercise.

Task 8: Change the application

Let's develop the first statement adding a new condition. After selecting the range, the user have to move the active cell to S4. So, we focus on the concept active cell and to the method of moving the active cell in a selected range. See the new statement of the exercise in the image presented in Fig. 8. 


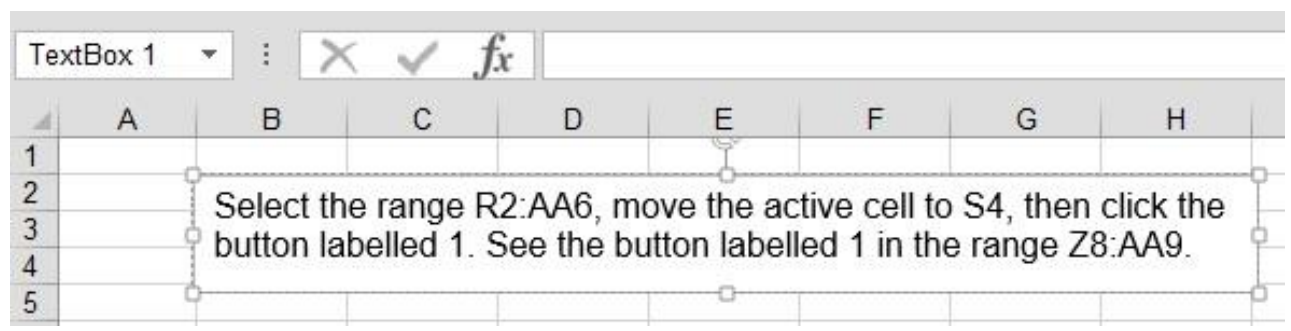

Fig. 8. Updated statement introducing a new concept

Task 9: Save the new application

In order to create a new exercise, save the application containing the new statement with the name Design2 in the same Excel Macro-Enabled Workbook (*.xlsm) format. Task 10: Modify the procedure in order to assure the logic of the new interactivity The procedure assign to the button labelled 1 will be updated, adding a condition and mod- ifying the messages in the two situation: both actions are solved or one of them is wrong. Another version of this application will treat each of the four situations. The procedure adapted for the simplest treatment for the composed condition is presented in the image of the Fig. 9.

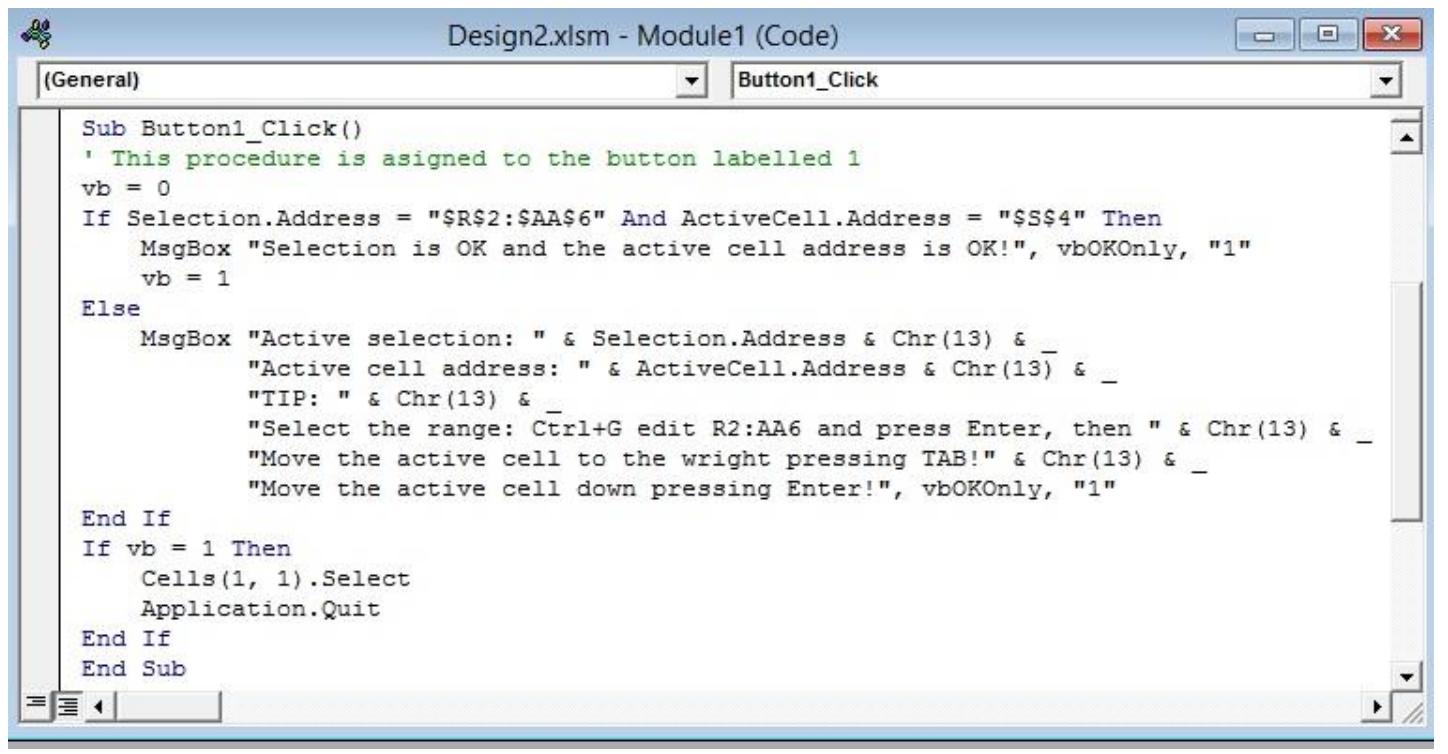

Fig. 9. The procedure updated corresponding to the new statement

Task 11: Test the new functionality and check the updated messages

Testing the new version of this application we can highlight three basis steps in assisted didactics design: a) Creating the statement in a specific context, b) Including objects and assigning procedure for interactivity, c) Testing functionality and creating specific messages. Integrating this exercise in an eEducation framework, we can highlight two more features both for e-Classroom and eClass: developing personalized statements applications and assuring functionality in different versions of the software environment.

\section{Conclusions}

This paper developed as a theoretical study in educational research describes an approach in order to differentiate levels of knowing, such as: lexical, terminological and conceptual, in order to pass from apprehension to comprehension through 'learning' defined as a specific human activity; as a result, there are presented the main principles of the teacher assisted learning system, developed in a standard e-Classroom in e-Education; eEducation could be developed as an informatics application of e-Science in e-Society, and these principles have to be integrated in 
standard assisted instruction applications, supporting the design of specific didactic activities. At the same time, these principles have to be integrated in standard assisted didactics design, as a recursive process in training the new teachers. In e-Classroom, the classwork involves the object language and the meta-language as two variables which integrate the fieldwork in the deskwork, as an environment for the basis specific competences. In e-Classroom the discipline theorized emerges in the discipline practiced and both converge in an assisted learning system.

\section{References}

[1] R. Jenkins, "Foundations of Sociology", Towards a Better Understanding of the Human World. New York: Palgrave MacMillan, 2002, ISBN: 0-333-96050-5, pp. 5-8, 40-46.

[2] J. Grix, "The Foundations of Research", London: Palgrave MacMillan, 2004, ISBN: 1-403-92145-8 paperback, pp. 5767

[3] J. A. Goguen, "Ontology, Society, and Ontotheology", Department of Computer Science \& Engineering, University of California at San Diego, USA. Available:http://cseweb.ucsd.edu/ goguen/pps/f ois04.pdf

[4] J. Mason, "Qualitative Researching", London: SAGE Publications Ltd, 2002, ISBN: 0761974288 (pbk) pp. 16-17

[5] S. A. Othman, "Abstract Impact of the Lexical Problems upon Translating of the Economic Terminology", Authorized by Al-Nasser University's Research Office, 2013, [Online]. Available: http://ebookbrowsee.net/abstract-impactof-the-lexical-problems-upon-translatingof-the-economic-terminology-pdfd658557833

[6] M. J. B. Finatto, "Metaphors in Scientific and Technical Languages: Challenges and Perspective", D.E.L.T.A., 26: especial, pp. 645-656, 2010 [Online]. Available:http://www.scielo.br/pdf/delta/v26nsp e/v26nspe12.pdf

[7] H. Skorczynska, "Metaphor in scientific business journals and business periodi- cals: an example of the scientific discourse popularisation", Ibérica 3, 2001 [Online].Available:http://www.aelfe.org/ documents/text3-Skorczynxka.pdf

[8] G. Zamfir, "Learning Paradigms in eSociety", Informatica Economica, Volume 17, no. 3, 2013, DOI: 10.12948/issn14531305/17.3.2013.09, [Online].Available:http://revistaie.ase.ro/ content/67/09\%20-\%20Zamfir.pdf

[9] C. E. Shannon, "Programming a Computer for Playing Chess" Philosophical Magazine, Series 7, Volume 41, No. 314 March 1950, http://www.tandfonline. com/doi/abs/10.1080/1478644500852179 6 ?queryID=\%24\% 7BresultBean.queryID \%7D\#.U8Y0jHmKCoA, http://vision.unipv.it/IA1/Programminga ComputerforPlayingChess.pdf

[10] J. G. Carbonell, R. S. Michalski, T. M. Mitchell, "Machine Learning: A Historical and Methodological Analysis" AI Magazine Volume 4 Number 3 (1983) (C) AAAI)

[11] G. Valentini, "Current and planned research", February 16, 2014 [February 18, 2014]http://homes.di.unimi.it/ valenti/pd f/vale.current.future.research.pdf

[12] N. Behl, V. Manocha, K. Chauhan, "Implementation Of Brain Computer Interface", International Journal of Engineering Research and Applications (IJERA), Volume 1, Issue 3, 2011, pp. 807-812, and ISSN: 2248-9622, [Online]. Available:http://www.ijera.com/papers/vol\%20 1\%20issue\%203/YG013807812.pdf

[13] C. Wasko, "What Teachers Need to Know About Augmented Reality Enhanced Learning Environments", TechTrends, Volume 57, Issues 4, July 2013, ISSN: 8756-3894 (Print) 15597075

(Online).Available:http://link.springer.co $\mathrm{m} /$ journal/11528/57/4/page/1

[14] G. Zamfir, "Theoretical and Factual Meaning in Assisted Instruction", Informatica Economica, Volume 15, no. 2, 2011, ISSN 1453-1305, EISSN 18428088,[Online].Available:http://revistaie.a se.ro/content/58/09\%20-\%20Zamfir.pdf 
[15] G. Zamfir, "Quality-Quantity Paradigm in Assisted Instruction", Journal of Applied Quantitative Methods, Volume 5, Issue 4, 2010, and ISSN: 1842-4562, [Online]Available:http://www.jaqm.ro/iss ues/volume-5,issue-4/pdfs/3_zamfir.pdf
e-Classroom", Informatica Economica, Volume 16, no. 3, 2012, ISSN 14531305, EISSN 1842-8088, [Online]. Available:http://www.revistaie.ase.ro/content/63 /11\%20-\%20Zamfir.pdf

[16] G. Zamfir, "Concepts Map Approach in

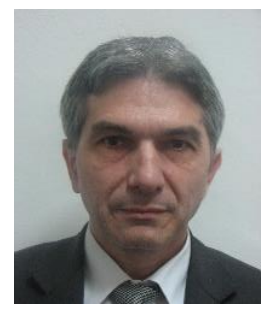

Gabriel ZAMFIR has graduated the Faculty of Planning and Economic Cybernetics in 1984 when he was distributed as analyst in the Research Institute for Computer Technique. In 1993, he joined the staff of the Bucharest University of Economics. In 2000, he finalized the doctoral thesis Computer Assisted Instruction in Economics. Currently he is full Professor of Computer Assisted Instruction within the Department for Training the Teachers, involved in designing education for metacognitive disciplines. 